\title{
AS ANALOGIAS E METÁFORAS NO ENSINO DE CIÊNCIAS À LUZ DA EPISTEMOLOGIA DE GASTON BACHELARD
}

Beatrice L. de Andrade (Aluna de Mestrado em Educação, UFSC; Bolsista CNPq) Arden Zylbersztajn (Departamento de Física, UFSC) Nadir Ferrari (Departamento de Biologia Celular, Embriologia e Genética, UFSC)

Este trabalho tem por objetivo apresentar as observações epistemológicas de Bachelard acerca da linguagem metafórica e analógica na ciência e no ensino de ciências. Tomando como base os conceitos de obstáculos epistemológicos e pedágogicos, são discutidas as reflexões de alerta crítico daquele autor com relação aos perigos inerentes ao uso de analogias e metáforas na ciência e no ensino de ciências.

\section{INTRODUÇÃO}

Atualmente, as questões lingüisticas têm atraído grande parte da atenção de pesquisadores em educação devido a sua grande importância no processo de construção da ciência e do conhecimento individual do ser humano. A linguagem metafórica e analógica, principalmente, passou a constituir uma linha com muitos pesquisadores no mundo todo, preocupados com suas possíveis utilizações e abordagens e com os seus efeitos na educação. Autores como Cachapuz (1989), afirmam que a linguagem das ciências tem suas próprias características e regras, com a predominância de definições e de um estilo impessoal que, em um contexto educacional, não favorece a função interpretativa/explicativa da linguagem, mas sim, a sua função de transmissão do conhecimento, isto é, com foco na comunicação entre o professor e o aluno, onde o mais importante é avaliar se a informação foi corretamente transmitida. Sustenta que uma das maneiras de se usar um estilo menos rígido e mais expressivo no ensino de ciências, consiste no uso de linguagem metafórica, que facilita a transferência do conhecimento de um domínio conceitual para outro.

Adrover e Duarte (1995), valorizam também a utilização de analogias como uma estratégia pedagógica no processo de ensino aprendizagem. Consideram o processamento analógico da informação, como uma estratégia central e uma característica distintiva do pensamento humano. Eles afirmam que

"a estratégia analógica de instrução consiste em uma modalidade de explicação, onde a introdução de novos conhecimentos por parte de quem ensina, se realiza a partir do estabelecimento explícito de uma analogia com um domínio de conhecimento mais familiar e melhor organizado, que serve como um marco referencial para compreender a nova informação, captar a estrutura da mesma e integrá-la de forma significativa na estrutura cognitiva." 
Nesta mesma linha de pensamento, Coracini (1991), assinala que "os conceitos metafóricos estão de tal modo arraigados à nossa cultura que estruturam nossas atividades diárias e científicas de forma imperceptível e inconsciente; são aliás, constitutivos da forma de pensar e agir de uma época".

Contudo, apesar das vantagens da utilização da linguagem metafórica e analógica, uma concepção empirista da ciência, segundo Perelmam (1987)

"não concederá à analogia mais do que papel heurístico, será eliminada a partir do momento em que tenha exaurido o seu papel, só permanecendo os resultados das experiências que ela pode sugerir: 0 seu papel será de andaimes de uma casa em construção, que são retirados quando o edifício está terminado".

Afirma que este papel heurístico das analogias, isto é, "sua capacidade de conduzir à descoberta e a resolução de problemas, não é contestado quando se trata de explorar um domínio desconhecido, de sugerir a idéia daquilo que não é cognoscível". Assim, "um modelo extraído de um domínio conhecido fornece um instrumento indispensável para guiar a investigação e a imaginação".

Pesquisadores nesta área têm estudado desde o papel da linguagem metafórica no processo cognitivo humano até abordagens metodológicas baseadas na utilização de analogias para se ensinar ciências, como é o caso do trabalho desenvolvido por S. M. Glynn (1991), chamado "T.W.A. - Teaching With Analogies" (Ensinando Com Analogias). Este modelo de ensino com analogias foi desenvolvido a partir da análise de livros texto de ciências e consta de seis passos metodológicos para se ensinar com analogias, com o objetivo de introduzir uma abordagem sistematizada, visando reduzir possíveis desvantagens decorrentes da utilização dessa forma de linguagem.

Apesar de todas as vantagens e da necessidade, segundo alguns autores, da utilização da linguagem metafórica no ensino de ciências, não podemos deixar de levar em conta alguns problemas que podem derivar de sua utilização de forma equivocada ou pela falta de sistematização para o seu uso.

Devemos ter cuidado com o uso de analogias e metáforas apresentadas nos livros didáticos pois, em geral, não parece haver preocupação com a forma de abordagem dessas analogias nos livros, ou seja, não se consegue estabelecer se as apresentações obedecem a alguma abordagem sistematizada. Estas apresentações, particularmente em Biologia, não evidenciam uma preocupação com as características do conceito-análogo (isto é, aquele que é mais familiar ao aluno) que não serão utilizadas como referências para se pensar sobre conceito-alvo (ou seja, aquele que se pretende ensinar). Isto pode contribuir para a formação ou reforço de concepções alternativas, baseadas justamente em aspectos onde o análogo e o alvo não se correspondem.

Um dos autores que mais fortemente alertou para os perigos da má utilização de analogias e metáforas na ciência e no ensino de ciências foi Gaston Bachelard que, no seu livro "A formação do espírito científico", de 1938, introduziu a noção de obstáculo epistemológico, 
fazendo uma análise epistemológica e psicológica dos obstáculos à formação do conhecimento científico.

Estes obstáculos estariam fundamentados na experiência primeira, no conhecimento geral, no abuso das imagens usuais, no conhecimento unitário e pragmático, no substancialismo, no realismo, no animismo e no conhecimento quantitativo, e seriam as causas da "estagnação e até regressão do progresso da ciência".

Com sua visão racionalista, Bachelard faz uma análise baseada em exemplos do que ele considera conhecimento pré-científico (antigüidade clássica até o final do século XVIII) onde estas características (obstáculos) estavam fortemente presentes e onde dominava uma linguagem metafórica, com uso de imagens e generalizações que guiavam este pensamento pré-científico para uma visão concreta e imediata, que impedia o processo de abstração necessária para a formação do espírito científico. Apesar de não possuir em sua obra textos exclusivamente voltados para a questão educacional, introduz a noção de obstáculo pedagógico, derivado dos mesmos obstáculos ao conhecimento científico.

Para Bachelard, as dificuldades de abstração a partir dos fenômenos concretos entrevam o pensamento científico. Segundo ele, os obstáculos vindos da experiência com a realidade fenomenológica levam o "pensamento científico para construções mais metafóricas que reais" e podem se tornar uma barreira, impedindo o pensamento abstrato, necessário para seguir a via psicológica normal do pensamento científico.

O trabalho de Bachelard neste livro sobre a formação do espírito científico contribuiu imensamente para a compreensão de como a forma da linguagem pode dificultar o trabalho do cientista e constituir um obstáculo epistemológico ao pensamento científico. Para este autor, a noção de obstáculo epistemológico pode ser estudada tanto no desenvolvimento histórico do pensamento científico, como também na educação, pois estes mesmos obstáculos constituemse em obstáculos pedagógicos para o ensino de ciências.

Neste trabalho temos por objetivo analisar as observações epistemológicas de Bachelard acerca da linguagem metafórica e analógica na ciência e no ensino de ciências. Inicialmente, situaremos alguns aspectos gerais da filosofia de Bachelard, especialmente com relação ao seu livro "A formação do espírito científico". Em seguida, colocaremos as posições de Bachelard com relação ao uso analogias e metáforas na ciência e no ensino de ciências, com extratos da obra citada acima. Por fim, concluiremos com uma discussão sobre as posições de Bachelard e sua contribuição para a área de pesquisa sobre a linguagem metafórica e analógica, colocando nossa posição acerca do assunto.

\section{BACHELARD E OS OBSTÁCULOS EPISTEMOLÓGICOS E PEDAGÓGICOS}

Gaston Bachelard nasceu em 27 de junho de 1884 e morreu em 16 de outubro de 1962 na França. Trabalhou questões epistemológicas na Física, na Matemática e na Química e possui uma extensa obra que apresenta um caráter dual, tendo trabalhos no campo da ciência e da epistemologia - o Bachelard diurno - com os livros publicados de 1928 à 1953, e no campo da poética - o Bachelard noturno - com os livros publicados de 1942 a 1961. Em sua obra não há textos exclusivamente voltados para a questão educacional, mas freqüentemente ele pontua suas análises filosóficas com interpretações a respeito do conhecimento científico na 
escola, sendo que, no livro "A formação do espírito científico" de 1938, Bachelard ressalta a necessidade dos professores conhecerem as concepções prévias dos alunos (seus conhecimentos anteriores ao processo de ensino) e coloca a problemática do obstáculo pedagógico: os obstáculos que impedem o professor de entender por quê o aluno não compreende (Lopes, 1996).

Maria Eduarda Santos (1991), faz uma ampla análise do trabalho de Bachelard sobre os obstáculos epistemológicos e a relação com as concepções alternativas, que sintetizaremos a seguir.

Segundo Santos, a concepção de Bachelard sobre o progresso da ciência é a de que esse não é linear, mas sim descontinuísta, dialético e inacabado. Na perspectiva bachelardiana, a ciência nos põe em presença de revoluções e não de evoluções; o avanço da ciência se dá portanto por descontinuidades ou rupturas onde a ruptura é um não, é uma negação a um passado de erros.

Uma das preocupações epistemológicas de Bachelard é investigar as fontes destas rupturas. Conclui que elas se relacionam com o fato, muitas vezes ignorado pela ciência, de que o sujeito coloca muito de si no próprio ato de conhecer; de que impregna o conhecimento científico de traços subjetivos, imaginários, muitas vezes do foro afetivo. São tais traços que fazem com que 0 ato de conhecer permaneça eivado (contaminado) de impurezas que escapam ao controle dos cientistas. Admite pois que há um inconsciente científico que perturba a atividade científica, ou seja, que há elementos inconscientes na base do conhecimento. Dessa investigação emerge a teoria central da reflexão bachelardiana - a teoria dos obstáculos epistemológicos.

Santos coloca que, para Bachelard, o inconsciente do espírito científico é a fonte primordial de contra pensamentos, mais ou menos disfarçados, baseados em dados sensoriais, que dificultam a emergência de valores racionais. É a estas resistências do pensamento ao pensamento que Bachelard chama de obstáculos epistemológicos. Para ele são os conhecimentos subjetivos, essencialmente do foro afetivo, que entravam o conhecimento objetivo. Estes conhecimentos dizem respeito a aspectos intuitivos, imediatos e sensíveis; a experiências iniciais; a relações imaginárias; a conhecimentos gerais, unitários e pragmáticos; a perspectivas filosóficas empiristas, realistas, substancialistas e animistas; a interesses, hábitos e opiniões de base afetiva, etc. São erros, investidos de tal energia psíquica, que se tornam tenazes e resistentes a toda mudança.

Bachelard, em "Formação do espírito científico", tipifica as principais categorias de obstáculos ao progresso da ciência. Paralelamente, faz referência a situações pedagógicas onde estas mesmas categorias de obstáculos são uma barreira à apropriação do conhecimento científico. Obstáculos epistemológicos que são obstáculos pedagógicos, uma vez que obstruem a atividade racional do aluno. Destes, Santos destaca:

a) $O$ conhecimento geral é um conhecimento vago, que imobiliza o pensamento. Fornece respostas demasiado vagas, fixas, seguras e gerais a qualquer questionamento. Dá confirmações fáceis a hipóteses imediatas. Em pedagogia, o problema agrava-se, pois a idéia do geral aparece imediatamente adaptada à idéia comum. Fornece a mesma resposta para todas as questões, desqualifica experiências de detalhe. Por exemplo, a respiração, que os alunos pensam que é uma troca gasosa 
que se limita ao nível dos pulmões, ou então as plantas, que recebem os "alimentos" já prontos pelas raízes. Estas idéias gerais se tornam certezas, que imobilizam a razão, privando-os de uma motivação real para se questionarem sobre os aspectos particulares dos mesmos fenômenos.

b) A experiência primeira, pitoresca, concreta, fácil, é a experiência situada antes e acima da crítica, que capta o imediato, o subjetivo; que tem dificuldade de abandonar o pitoresco da observação; que subordina a prática científica ao efeito das imagens; que dá grande atenção ao que é natural; que aborda fenômenos complexos como se fossem fáceis; que tem a marca de um empirismo evidente. Na educação em ciência, com maioria de razão, o colorido pitoresco de certas manifestações naturais seduzem os alunos. Tal admiração opõe-se à procura do "porquê" e do "porque não" de tais fenômenos. Este obstáculo está relacionado com evidências empíricas sobre concepções alternativas - dependência de aspectos óbvios da percepção. Um exemplo disso, é o caso do eletrismo do século XVIII, que foi transformado em divertimento de salão, distraindo a atenção dos cientistas dos aspectos essenciais do fenômeno.

c) Obstáculo verbal é uma falsa explicação obtida à custo de uma palavra explicativa. Uma só palavra, funcionando como uma imagem, pode ocupar o lugar de uma explicação. Por exemplo a palavra esponja, como veremos com mais detalhes adiante, é uma palavra obstáculo. É usada como auxiliar do pensamento, numa extensão abusiva de imagens familiares. Exprime os mais variados fenômenos na falsa convicção de que os explica. Também em situações pedagógicas há palavras que, dizendo respeito a linguagem aprendida em contextos não científicos e com conotações divergentes ou com uma significação simbólica para o sujeito, constituem barreira ao ensino formal das ciências. Os exemplos que Bachelard apresenta sobre o obstáculo verbal estão relacionados com o uso desajustado de imagens, analogias e metáforas, quando, na prática pedagógica, tendem a reforçar as concepções alternativas radicais no imaginário infantil.

d) O conhecimento pragmático traduz-se na procura do caráter utilitário de um fenômeno como princípio de explicação. Bachelard afirma que muitas generalizações exageradas provêm de uma indução pragmática ou utilitária. Em pedagogia, constata-se que quando os alunos se referem a aspectos utilitários dos conceitos, como por exemplo: "a fotossíntese é a função que purifica o ar que nós respiramos", parece que isto é suficiente para definir os conceitos.

e) O obstáculo animista traduz-se numa tendência para, de um modo ingênuo, animar, atribuir vida e muitas vezes propriedades antropomórficas a objetos inanimados. $\mathrm{Na}$ história da ciência, sobretudo no estágio pré-científico, recorria-se, freqüentemente, a fenômenos biológicos como meios de explicação para fenômenos físicos, o que constituía um obstáculo à compreensão destes - valorização do princípio vital. Em educação em ciência, o obstáculo animista constitui grande dificuldade à apropriação dos conceitos científicos. A compreensão das representações científicas exige uma ruptura com as representações animistas.

Segundo Santos, não há qualquer continuidade entre a ciência e o senso comum, na perspectiva epistemológica de Bachelard. No conhecimento comum, os dados são como 
que oferecidos gratuitamente pela realidade, resultam da percepção imediata. No conhecimento científico, os "dados" resultam de uma reflexão, provêm de um longo percurso através da ciência teórica, de um grande afastamento da percepção sensível. Não têm, pois, nada de imediato.

No conhecimento científico atual, toda observação está impregnada de teoria - é precedida de um problema, de uma hipótese, de algo especulativo. Não radica em evidências do senso comum, mas em construções tentativas, modelos teóricos de aproximação à realidade, que exigem o desenvolvimento de pensamentos divergentes e um rigoroso controle das hipóteses avançadas.

Para Bachelard, há uma grande ruptura entre o conhecimento científico e o conhecimento comum pois, enquanto o conhecimento vulgar permanece ligado a princípios empiristas de generalidade, de utilidade, de finalismo, o conhecimento científico está cada vez mais ligado a princípios racionais, é cada vez mais teórico.

\section{BACHELARD E AS ANALOGIAS E METÁFORAS}

Vimos no item anterior as posições de Bachelard, presentes em "Formação do espírito científico", com relação ao obstáculo configurado pelas observações empíricas e subjetivas da natureza, pelo senso comum. Contudo, interessa-nos particularmente, as observações feitas por Bachelard com relação à utilização de analogias e metáforas na construção do conhecimento científico e no ensino de ciências.

Segundo Bachelard, a utilização dessa forma de linguagem, intimamente ligada às concepções prévias dos alunos, pode induzir a formação/reforço de obstáculos como por exemplo, o substancialismo e o animismo.

Já no capítulo "O primeiro obstáculo: a experiência primeira", pode-se perceber claramente observações em que Bachelard mostra a sua posição contra o uso de imagens na ciência e no ensino da ciência. Ele diz que "uma ciência que aceita imagens, é mais que qualquer outra, vítima das metáforas", por isso "o espírito científico deve lutar sempre contra as imagens, contra as analogias, contra as metáforas"(Bachelard, 1996, p.48).

Bachelard afirma que, nas classes do curso elementar, o pitoresco e as imagens causam desastres quando são utilizadas experiências que deixam de lado os fenômenos essenciais, como por exemplo as que utilizam aparelhos esquisitos em aulas de física ou as com explosões em aulas de química.

Por essa razão, faz uma crítica ao uso de experiências muito marcantes e cheias de imagens no ensino elementar, que ele considera como "falsos centros de interesse". Coloca a experiência como "uma fuga do verdadeiro espírito científico", por provocar um esvaziamento do seu princípio fundamental. Considera "indispensável que o professor passe continuamente da experiência para a lousa a fim de extrair o mais depressa possível o abstrato do concreto" pois, "quando voltar à experiência, estará mais preparado para distinguir os aspectos orgânicos do fenômeno" (p.50).

Bachelard utiliza, no capítulo IV, a palavra esponja, para "caracterizar hábitos de natureza verbal como obstáculos do pensamento científico, considerando um caso onde uma única imagem ou até uma única palavra constitui toda a explicação" (p.91). 
O exemplo da simples palavra esponja, no período pré-científico, permitia expressar os fenômenos mais variados, "não sendo necessário aos que a utilizavam explicá-la, porque sua função parecia clara e distinta" (p.91). Na imagem generalizada da esponja, os pesquisadores da antigüidade, utilizavam-se da característica esponjosa para explicar fenômenos como, por exemplo, o da dissolução do ar na água, idéia que Réaumur considerava adequada para explicar porque 0 ar se deixava comprimir pelos pesos, "considerando o ar como se fosse algodão, lã, esponja, e muito mais esponjoso do que todos os outros corpos ou reunião de corpos com os quais pode ser comparado"(Réaumur citado por Bachelard, p.92).

Benjamim Franklin tenta também aplicar as experiências elétricas a partir da experiência primitiva da esponja que ele considera como uma verdadeira categoria empírica. Para ele

"a matéria comum é uma espécie de esponja para o fluido elétrico; $A$ esponja não absorveria água se as partes da água não fossem menores que os poros da esponja; (...) enfim, a absorção seria muito rápida se em vez de atração, houvesse entre as partes da água uma mútua repulsão que concorresse com a atração da esponja. É exatamente o caso em que se encontra a matéria elétrica e a matéria comum" (Franklin citado por Bachelard, p.95).

Bachelard considera que a utilização excessiva de imagens que se acumulam prejudica a razão, pois seu lado concreto, apresentado sem prudência, impede a visão abstrata e nítida dos problemas reais. No período pré-científico "por um movimento pura e simplesmente lingüístico, os autores associavam uma palavra concreta a uma palavra abstrata, pensando terse feito avançar as idéias". Ele afirma que "para ser coerente, uma teoria de abstração necessita afastar-se bastante das imagens primitivas" alertando que, quando a aplicação da imagem "é utilizada de forma mais rápida e direta e menos controlada, a imagem se explica automaticamente e pode ficar confusa e complicada e adquirir uma caraterística substancialista" (p.94).

É bastante interessante observar que, já em 1785, havia autores que se preocupavam com o obstáculo apresentado pela imagem da esponja e com as dificuldades de se livrar dela. Bachelard cita J.-H. van Swinden que, no livro "Analogie de l' èletricité et du magnetisme", faz uma longa série de objeções contra "as múltiplas analogias por meio das quais pretendiam reunir, numa mesma teoria, eletricidade e magnetismo" (p.96). Seu pensamento deixou claro "que não se pode confinar com tanta facilidade as metáforas no reino da expressão", que as "metáforas seduzem a razão", que "são imagens particulares e distantes que, insensivelmente, tornam-se esquemas gerais" (p.97).

Bachelard analisa outros exemplos, onde imagens simplistas são propostas como explicativas. Um deles é o trabalho de Franklin, que registra em eletricidade o poder das pontas com a imagem de arrancar o pelo do rabo de um cavalo. Outro é o trabalho de Marat, em 1782, que explica a máquina elétrica comparando-a com uma bomba (p.100). Sobre a analogia da bomba (analogia hidráulica), Bachelard ressalta que a "ciência moderna serve-se da analogia da bomba para ilustrar algumas características dos geradores elétricos, mas é para tentar esclarecer as idéias abstratas de diferença de potencial e de intensidade de corrente". Coloca 
em contraste a observação: "no pensamento pré-científico a analogia hidráulica entra antes da teoria" enquanto que "no pensamento científico a analogia entra depois da teoria" (p.100). Alerta que "o perigo das metáforas imediatas para a formação do espírito científico é que nem sempre são imagens passageiras; levam a um pensamento autônomo, tendem a completar-se, a concluir-se no reino da imagem" (p.101).

Sobre o conhecimento unitário e pragmático, Bachelard cita os historiadores da química, que estudaram detidamente as teorias que, na Idade Média e no Renascimento, foram baseadas em amplas analogias. Ele se refere particularmente à obra de Hélène Metzger que reuniu tudo o que se referia às analogias paracelsistas que estabeleciam analogias entre os astros e os metais, entre os metais e as partes do corpo. Estas analogias estabelecem uma espécie de triângulo universal, que une o céu, a terra e o homem, tão convincente que foi utilizada para o tratamento de doenças: "A cada doença no homem, a cada desarmonia acidental de um órgão, o remédio apropriado é o metal correspondente ao planeta análogo ao órgão doente" (Metzger citada por Bachelard, p.109). Bachelard pergunta, se "é preciso dizer que tais analogias não ajudam nenhuma pesquisa? Ao inverso, provocam fuga de idéias, impedem a curiosidade homogênea que faz com que a paciência siga uma seqüência de fatos bem definida" (p.109).

No capítulo sobre o obstáculo substancialista, Bachelard afirma que a necessidade de substantificar as qualidades é tão grande que qualidades metafóricas podem ser propostas como essenciais. É o caso de Boerhaave que atribui à água, como qualidade primordial, a suavidade e como conseqüência dessa propriedade essencial, considera "a água quente como um dos principais remédios anódicos e paregóricos". Bachelard completa: "Percebe-se que a qualidade suave rolou de metáfora em metáfora, mas que, para Boerhaave, sempre indica uma qualidade profundamente substantificada. Não é preciso perder tempo mostrando a inutilidade evidente de tal forma de pensar"(p.137-138).

Bachelard, no capítulo "Psicanálise do realista", dá o exemplo da utilização de pedras preciosas e ouro em tratamentos médicos, que encanta e atrai os pacientes. Diz que

"essa atração e esse encanto são metáforas, a substantificação de um valor atribuído às pedras preciosas e ao ouro que serão utilizadas no tratamento médico. A alegria de possuir se substantifica. Propicia uma experiência íntima, um reconforto que torna inútil a verificação objetiva. Nessas opiniões dá-se a junção de uma experiência psicológica com uma médica, ou seja, a fusão de uma paixão verdadeira com uma idéia falsa. É a paixão verdadeira que constitui um obstáculo à correção da idéia falsa" (p.172-174).

Já no capítulo "O obstáculo animista", Bachelard se preocupa com as relações analógicas feitas entre os fenômenos biológicos e os fenômenos físicos, que constituiriam obstáculos para a compreensão destes. Ele se refere à atribuição, aos fenômenos físicos, de características próprias dos fenômenos biológicos, como fecundidade e vivacidade. Este é o caso da explicação de fenômenos elétricos pela vivacidade dos objetos eletrizáveis. Bachelard 
coloca que "essa explicação não é uma simples referência à obscura intuição da vida (...) é um desenvolvimento minucioso que aplica o fenômeno físico sobre o fenômeno biológico" (p.201).

O obstáculo animista também pode ser caracterizado pelo mito da digestão, onde aparecem inúmeras metáforas utilizadas pelos alquimistas, como por exemplo, "os corrosivos comuns, esfaimados como são, tentam devorar os metais a fim de matar a fome, atacam-nos com fúria" (p.217). Bachelard considera que esse "número de imagens, que um espírito científico julga, no mínimo inúteis, mostra com clareza seu papel explicativo suficiente para o espírito pré-científico" (p.217).

Por fim, Bachelard coloca no capítulo sobre a libido e conhecimento objetivo, "que alguém pode ainda afirmar que todas as metáforas estão gastas e que o espírito moderno, pela própria mobilidade das metáforas, venceu as seduções afetivas que já não emperram o conhecimento dos objetos" (p.240). Entretanto, coloca que "se alguém examinar o que se passa numa mente em formação, colocada diante de uma experiência nova, em uma aula de química por exemplo, ficará surpreso em encontrar antes de mais nada pensamentos sexuais" (p.240), ou seja, comparações onde os elementos de uma reação química teriam um o papel ativo (ácido - masculino) e o outro o passivo (base - feminino).

\section{CONCLUSÃO}

$\mathrm{Na}$ conclusão deste trabalho queremos esclarecer não ter sido nossa pretensão exaurir todas as nuances apresentadas por Bachelard acerca das analogias e metáforas em sua obra "A formação do espírito científico". Ainda assim, esperamos ter proporcionado uma visão geral das suas críticas presentes no livro, que servirão como base para a discussão a seguir.

Vimos na seção anterior as observações críticas de Bachelard acerca da utilização de analogias e metáforas na ciência e o ensino de ciências, principalmente aquelas do capítulo onde fala do obstáculo verbal. Contudo segundo Santos (1996), Bachelard coloca mais claramente no livro "L'activité racionaliste de la physique contemporaine" de 1951, que

"as imagens (...) são, ao mesmo tempo, boas e más, indispensáveis e prejudiciais, é preciso usá-las com medida enquanto são boas e desembaraçar-se imediatamente delas quando se tornam prejudiciais."

“ (...) há que desqualificar o uso figurativo de analogias, imagens imediatas e metáforas se constituírem uma ameaça à restauração do continuísmo, se derem primado ao realismo, se não forem psicanalisadas, se tenderem a transformar conceitos abstratos em elementos observáveis - em coisas; há que desqualificar o uso figurativo de analogias e metáforas quando pretendem ser imagens-reflexo, mais ou menos exatas, de uma realidade oferecida à investigação, ou seja, quando pretendem passar por cópias fiéis dessa realidade; há que as desqualificar quando se transformam em esquemas gerais que permanecem (obstáculos epistemológicos) em vez de assumirem um papel transitório". ( Bachelard, 1951, citado por Santos, 1991) 
Santos coloca que, não obstante, Bachelard admite, na obra "L'air et les songes: essais sur l'imagination du movement", de 1943, que "criar uma imagem é verdadeiramente dar a ver, o que tinha sido mal visto, o que se tinha perdido na familiaridade preguiçosa, é então um objeto novo para um olhar novo". Ela sumariza:

"Bachelard admite uma utilização científica, embora efêmera, de certas imagens e metáforas se estas não atuarem apenas como fatores de distração à construção dos conceitos científicos. Se não fizerem correr 0 risco de tomar os andaimes pelo vigamento. Ele defende o conceito contra a imagem, passando pela imagem. Daí que é preciso, diz, 'desrealizar' metáforas, e imagens ingênuas".( Bachelard, 1943, citado por Santos, 1991)

Portanto, podemos perceber que Bachelard não é contra toda e qualquer utilização de analogias e metáforas mas sim, contra as que podem reforçar concepções da observação empírica, do senso comum, ou quando elas se tornam cópias fiéis da realidade, impedindo a compreensão do que se pretende ensinar, tornando-se ou reforçando obstáculos epistemológicos e pedagógicos.

Concluindo, consideramos que a linguagem metafórica e analógica é uma forma de raciocínio inerente ao ser humano. Tanto na ciência quanto na educação, pode ser tomada como uma ferramenta útil no processo de explicação dos conceitos científicos. Colocamo-nos assim ao lado de vários autores que, nas últimas décadas, têm tomado a linguagem metafórica e analógica como uma forma legítima de pensamento, que auxilia no processo de aprendizagem do conhecimento científico por aproximar os conceitos considerados teóricos e abstratos das ciências de análogos mais familiares e melhor compreendidos pelos alunos.

Concordamos plenamente com Bachelard quanto ao perigo das analogias e metáforas serem mal utilizadas, serem tomadas como cópias fiéis da realidade e se transformarem em esquemas gerais que permanecem, em vez de assumirem um papel transitório. É importante ressaltar, em educação, a necessidade de um maior preparo das analogias e metáforas, pelo professor, que as utiliza muitas vezes de forma espontânea e inadequada.

\section{REFERÊNCIAS}

ADROVER, Juan F.; DUARTE, Anibal. (1995). El uso de analogias en la enseñanza de las ciências. Programa de estudios cognitivos, Instituto de investigaciones psicologicas, Facultad de psicologia, Universidade de Buenos Aires.

BACHELARD, Gaston (1996). A formação do espírito científico: contribuição para uma psicanálise do conhecimento. Tradução de Estela dos Santos Abreu, Rio de Janeiro/BRA: Contraponto, 316p. Tradução de: La formation de l'espirit scientifique: contribution a une psychanalyse de la connaissance. Paris/FRA: Librairie Philosofique J. Vrin, 1938.

CACHAPUZ, Antônio (1989). Linguagem metafórica e o ensino de ciências. In: Revista Portuguesa de Educação, 2(3), 117-129. 
CORACINI, Maria J. R. F. (1991). A metáfora no discurso científico: expressão de subjetividade? In: Um fazer persuasivo: o discurso subjetivo da ciência. São Paulo/BRA: EDUC; Campinas/BRA: Pontes, p.133-147.

GLYNN, Shawn M. (1991). Explaining science concepts: A Teaching-with-Analogies Model. In: S. M. Glynn, R. H. Yeany, \& B. K. Britton (Eds.), The psychology of learning science (pp. 219-240). Hillsdale/NJ: Erlbaum.

LOPES, Alice R. C. (1996). Bachelard: o filósofo da desilusão. In: Caderno Catarinense de Ensino de Física, 13(3), p.248-273.

PERELMAN, Chaim (1987). Analogia e Metáfora. Enciclopédia Einaudi. Oral/Escrito Argumentação, v.11. Lisboa/POR: Imprensa Nacional/Casa da Moeda.

SANTOS, Maria E. V. M dos (1991). As concepções alternativas dos alunos à luz da epistemologia bachelardiana. In: Mudança conceitual em sala de aula, um desafio pedagógico. Lisboa/POR: Livros Horizonte, p.128-164. 